\title{
The Emotion of Self-Reflexive Anxiety
}

ABSTRACT: In this article, I provide an analysis of the widespread, intellectually fascinating, and existentially challenging phenomenon of self-reflexive anxiety in which we feel threatened by what or who we are (or have been or will become). I focus on those cases in which we take an event or action whose possible occurrence we attribute to ourselves to be expressive or constitutive of our identity. As I argue, depending on the kind of event we are dealing with, our descriptive self-conception, our self-esteem, or our evaluative self-conception are at stake. In all cases, we are confronted with a dialectic between self and other, activity and passivity inherent in our personhood or even in our agency. I demonstrate how my analysis is not only of intrinsic value, but it can also help us in achieving a better understanding of self-reflexive emotions in general and 'traditional' self-reflexive emotions like shame in particular.

KEYWORDS: self-reflexive emotions, anxiety, practical identity, shame, possible selves

\section{Introduction}

In the final meters of my climb to the summit of the Zugspitze, the highest mountain in Germany, I have to descend some pegs, walk some meters on the ridge, with a steel cable to my left and an abyss to my right, and climb two short ladders, before finally passing another steel cable leading me to the golden summit cross. There are crowds of tourists who, like me, want to reach the cross sparkling in the sun: they include people without any experience in mountaineering, young children, old people, all of them having reached the huge platform below the summit by cable car. They all are eager to ascend the final meters in order to take a picture to prove that they have been to the highest point in Germany. Right in front of me, one of the most impatient visitors loses his footing, then picks himself up and presses on. This is the moment when, for the first time that day, I become scared: 'If he's right above me on the ladder and slips again, he'll definitely take me and some other people with him into the depths', or so I think. In light of this thought, I am happy to give way to the oncoming traffic and to thereby increase the distance between him and me. But safety with regard to this outer threat does not end my anxiety. Maybe I, too, have overestimated my skills. What if I should slip? What if I start to feel dizzy? Had not this thought—namely that I might begin to feel dizzy-in combination with the sight of the abyss already started to elicit some kind of dizziness in me? I might fall down the precipice through a fault of my own or perhaps even of my own free will. 
Such a description demonstrates that fears and anxieties are not only or not always directed at outer objects-external objects or potential events brought about by something beyond ourselves. They can also be directed toward ourselves - the person we might be or events we might bring about. The example describes a situation in which I was confronted with the outer threat of being plunged into an abyss by someone else and, at the same time, the inner threat of falling into the abyss thanks to a fault of my own or of my own free will. The former phenomenon can be classified as world-directed, whereas the latter can be classified as self-directed. We evaluate ourselves in the face of a future event that we ourselves (at least in part) might bring about.

We know phenomena of self-reflexive anxiety from everyday life, and we know of them from psychology and psychopathology. For example, people are afraid of the bodily, cognitive, and social dimensions or consequences of their own fears (Reiss I99I); they are worried about their own worries (Wells 2007); they are afraid of failing final exams or of making embarrassing mistakes in public presentations (Spielberger and Vagg I995; Zeidner and Matthews 2005); they are afraid of saying something offensive in public or of doing harm to themselves (Clark and Radomsky 20I4; Radomsky et al. 20I4); and they are afraid of giving in to their undesirable cravings or habits or of becoming one of their dreaded possible selves (Markus and Nurius I986). Moreover, phenomena of self-reflexive anxiety have attracted the interest of existential philosophers and existentially inspired philosophers (Heidegger 2006; Kierkegaard 1980; Sartre I943; Schulz I965; Tillich 2000).

However, in philosophical and psychological theories of self-reflexive emotions, self-reflexive anxiety is rarely explicitly addressed (Konzelmann Ziv, Lehrer, and Schmid 20II; Lewis 2008; Taylor I985; Tracy, Robins, and Tangney 2007; Zinck 2008; Zinck 20II) and receives much less attention than 'traditional' self-reflexive emotions, such as guilt, shame, or pride. This leaves these accounts badly incomplete. Moreover, philosophical theories of fear and emotions give rise to the concern that self-reflexive anxiety might not be possible in the first place because to fear an event we need to be passive with regard to its occurrence (Gordon I987: 79-84), whereas in the phenomenon of self-reflexive anxiety we perceive ourselves as the 'source' of the threat.

In developing a theory of the widespread, intellectually fascinating, and existentially challenging phenomenon of self-reflexive anxiety, I aim to help fill this gap. Most importantly, I address the questions of how self-reflexive anxiety is possible and what the possibility and reality of self-reflexive anxiety tell us about human existence. Moreover, I demonstrate how my analysis helps us in achieving a better understanding of self-reflexive emotions in general and traditional self-reflexive emotions such as shame in particular.

As I have outlined elsewhere, the conceptual distinction between fear and anxiety that is characteristically drawn with reference to existential philosophy is notoriously vague (Tietjen 20I9: I IO-I I; for different views on what it may mean that 'fear' is directed at something 'specific', whereas 'anxiety' is characterized by its 'unspecificity', see Helm 200I: I04; Goldie 2009: I7-I9; Kurth 2018: 32-35). Therefore, I use the concepts of fear and anxiety roughly synonymously, 
designating both world- and self-directed emotional and mood-like phenomena. My main objective is to outline a systematic philosophical theory of the emotion of self-reflexive anxiety (for an analysis of the relation between my account of anxiety and those of Søren A. Kierkegaard, Martin Heidegger, and Matthew Ratcliffe, see Tietjen 2019).

In section one, I define self-reflexive emotions as emotions in which we either implicitly or explicitly evaluate ourselves. I point out three shortcomings of the scholarly debate on self-reflexive emotions that (partially) can be overcome by analyzing the phenomenon of self-reflexive anxiety. In section two, I provide a fine-grained analysis of the phenomenon of self-reflexive anxiety. I argue that self-reflexive anxiety is an emotion in which we take an aversive stance toward who we might be, might have been, or might become. In my analysis, I focus on those cases of self-reflexive anxiety in which we take an event or action whose possible occurrence we attribute to ourselves to be expressive or constitutive of our identity. As I argue, depending on the kind of event we are dealing with, our descriptive self-conception, our self-esteem, or our evaluative self-conception are at stake. In all cases, we are confronted with a dialectic between self and other, activity and passivity inherent to our personhood or even to our agency. Third and finally, I highlight some of the consequences of my analysis of self-reflexive anxiety for our understanding of self-reflexive emotions in general and shame in particular.

\section{Self-Reflexive Emotions}

According to a dominant view in contemporary philosophy of emotions, emotions are affective, evaluative, representational states of mind (Deonna and Teroni 20I 2; Goldie 2009; Helm 200I; Nussbaum 200I; Roberts 2003). As occurrent affective states of mind, they have a specific phenomenal quality; it feels a specific way to have an emotion. Moreover, emotions are intentionally directed toward particular objects in the world, which are represented in a specific way. Either the intentional mode (the way of being directed at the intentional content) or the intentional content itself (the object represented in a certain way) are taken to involve an emotion-specific evaluation called the formal object of the emotion (Deonna and Teroni 20I 2: 40-42; Teroni 2007). Different types of emotions such as fear and anger (among other things) differ from each other in virtue of their formal object - that is, the value property they ascribe to their material object. The formal object of fear, for example, is something like the property of being an aversive possibility (Roberts 2003: 193-95). Affectivity and intentionality of emotions are inextricably entangled with each other (Goldie 2009: I2-28, 50-83). Our evaluative stance reflects the concerns we have-that is, what we care about, what we take to be important and/or valuable (Helm 200I: 60-98; Roberts 2003: I4I-5I). In fear, for example, something we care about is experienced as threatened or endangered (Heidegger 2006: I40-42, I 84-9I).

The focus on the intentionality of emotions suggests defining self-reflexive emotions as emotions in which we either implicitly or explicitly evaluate ourselves rather than something different from ourselves (Zinck 2008). In doing so, they do 
not just refer to someone who, as a matter of fact, is identical to ourselves. They refer to ourselves as ourselves (Konzelmann Ziv 20I I).

The philosophical and psychological debates on self-reflexive emotions are largely characterized by an ambiguity regarding the concept of self-reflexive emotions. Quoting Julien Deonna, Raffaele Rodogno, and Fabrice Teroni is illustrative in this regard:

In fear and disgust, for example, what is evaluated-an approaching bear (as dangerous) or a rotten piece of food (as repellent)-is neither oneself nor something one has done. Other emotions, like guilt or remorse, are elicited by events in which the subject is clearly implicated: the locus of evaluation is an action or omission of mine for which I feel responsible. That being said, still other emotions, like shame, appear to involve the self in yet another way: in shame, the self has not only to be implicated in what is evaluated, but it also appears to be the emotion's focus of evaluation. (Deonna, Rodogno, and Teroni 20I 2: 83-84)

This definition is ambiguous regarding the question of whether self-attribution of a feature or event is sufficient for a self-reflexive emotion (as indicated by the emphasis on 'of mine') or whether we additionally have to feel responsible for having the feature, for having brought about the event, or for having performed the action in question (as indicated by the addition 'for which I feel responsible'). Whereas for some types of self-reflexive emotions (such as guilt) some form of responsibility attribution seems to be necessary, for others (such as shame)-and, therefore, for the category of self-reflexive emotions itself-this seems to be less clear. A similar ambiguity can be found in psychological theories of self-reflexive emotions that highlight that self-reflexive emotions involve a self-ascription of an event without drawing a clear conceptual distinction between agency, accountability, and responsibility. Therefore, they remain unclear as to which of these categories is 'most relevant to self-conscious emotions' (Tracy and Robins 2004: I09). As I argue below, the analysis of self-reflexive anxiety helps us to understand that this ambiguity is not a conceptual problem that can be resolved in favor of one or the other defining feature but rather reflects a dialectic inherent to our selfhood as such.

Moreover, the existing debate on self-reflexive emotions is focused for the most part on necessarily self-reflexive emotions like shame, guilt, embarrassment, or pride. More precisely, considering cases such as vicarious embarrassment, collective guilt, or pride of someone else's achievements, we can state that the debate is focused on emotions that in the first place are self-reflexive. In philosophy as well as in psychology, self-reflexive emotions are commonly contrasted with so-called basic emotions, such as fear or disgust (Fontaine 2009; Zinck 2008). The latter are claimed to be automated response mechanisms that are experienced across all cultures, shared with other animals, and distinguishable by specific bodily reactions. What is striking about this comparison is that types of self-reflexive emotions, such as guilt, remorse, or shame, are compared with 
tokens of non-self-reflexive emotions, such as being afraid of an approaching bear, as in the case cited above. Complex self-reflexive cases of non-necessarily self-reflexive emotions like anxiety or anger rarely play a central role in theories of self-reflexive emotions although they certainly exist, their existence is never explicitly denied (at least not to my knowledge), and occasionally, they are even explicitly mentioned (Tracy and Robins 2004).

Finally, the debate is focused on past- or present-directed emotions. More precisely, considering cases such as prospective shame or anticipatory guilt (Deonna, Rodogno, and Teroni 2012: I78; Velleman 2003), the debate is focused on emotions that in the first place are directed at one's past or present self or at past or present characteristics or actions of oneself. Taking for granted that fear is a future-directed emotion, it is not surprising that, as Deonna, Rodogno, and Teroni state in the quotation, in the emotion of fear 'what is evaluated. . . is neither oneself nor something one has done'. Prima facie, what is to be expected if fear is considered as a self-reflexive emotion is that it is not directed at who we are but at who we might become; what is to be expected is not that it is directed at what we have done but at what we might do. Although the existence of future-directed self-reflexive emotions is never explicitly denied, they are not usually the center of attention (Kurth 20I 8: I).

Since anxiety is an emotion that has paradigmatic self-reflexive and non-self-reflexive cases, and since it paradigmatically (although, as we will see, not necessarily) is directed at future events and actions and/or at our future self, an analysis of the emotion of self-reflexive anxiety promises not only to be of intrinsic value but also to enrich our understanding of self-reflexive emotions in general (as an analysis of other non-necessarily or future-directed self-reflexive emotions such as anger or self-confidence also does).

\section{Self-Reflexive Anxiety}

In order to answer the question of what self-reflexive anxiety is, I start with a definition of the emotion of anxiety. As outlined above, I conceive of emotions as affective states of mind that are directed at specific objects in the world that are represented in a specific way. Moreover, I assume that different emotions can be distinguished in virtue of their formal object. Although it is a matter of ongoing debate as to how precisely the formal object of fear ought to be conceptualized (Tappolet 2010: 328), here I follow Robert Roberts's definition of the formal object of fear as 'the property of being an aversive possibility' (2003: 193-202). This definition is a good starting point because contrary to other definitions like 'the (disagreeable) dangerous' (Goldie 2009: 28-3 I; Lyons I980: IOI) it does not have an objectifying tendency. It neither reduces the objects of fear to imminent threats nor to objects that constitute a 'severe physical, social, or psychological harm' (Roberts 2003: I96). Instead, it allows for a variety of certain and uncertain dangers threatening whatever we personally may care about and, therefore, is in line with my usage of the concept of anxiety as an umbrella term. 


\section{Evaluations}

Self-reflexive and non-self-reflexive anxiety have the same formal object (being an aversive possibility) but different material objects. In the phenomenon of self-reflexive anxiety, we either implicitly or explicitly evaluate ourselves. We take an aversive stance toward who or what we as persons (either individually or as persons per se) might be, might have been, or might become. Some cases of self-reflexive anxiety are dependent upon our being in a specific situation in which an event is taking place or is going to take place (Ereignissituation), or an action is being undertaken or demanded (Handlungssituation), as in the introductory example. We fear the event-that is, we experience its occurrence as uncertain and the event itself as aversive. We attribute its possible occurrence to ourselves, and we evaluate ourselves in terms of its possible occurrence. Other cases of self-reflexive anxiety are independent of such specific situations-as in, for example, the fear that one is going to be depressed or a general kind of fearfulness over the possibility of becoming insane (James 2002: I60; Markus and Nurius 1986). I exclusively address phenomena of the first kind, whereas a more comprehensive analysis of self-reflexive anxiety would also have to account for phenomena of the second kind. All forms of self-reflexive anxiety addressed here thus involve two different evaluations: first, an explicit self-evaluation: we take an aversive stance toward what or who we might be, might have been, or might become; and second, an implicit self-evaluation: we fear an event whose possible occurrence we attribute to ourselves. Within one and the same emotion, the focus of attention can shift from the event to ourselves and backward (Goldie 2009: $5 \mathrm{I}-72)$.

To illustrate these claims, I return to the example in the introduction. There, I described a situation in which I was confronted with the outer threat of being plunged into an abyss by someone else and, at the same time, the inner threat of falling into the abyss thanks to a fault of my own or of my own free will. The former phenomenon can be classified as world-directed, whereas the latter can be classified as self-directed: we evaluate ourselves in the face of a future event that we ourselves (at least in part) might bring about. This-the self-evaluation whose material object is me as the source of my falling-is the first evaluation that is involved in the phenomenon described in this example; the second evaluationwhose material object is the (self-induced) falling-is the evaluation of the event itself. More precisely, the example provides a description of three different forms of self-reflexive anxiety that differ in the way the relationship between oneself and one's falling is construed:

I. being afraid of one's own bodily reactions (becoming dizzy and, therefore, falling down the precipice);

2. being afraid of one's own failure (accidentally making a fatal mistake in the mountains and, therefore, falling down the precipice);

3. being afraid of one's own actions (intentionally jumping down a precipice). 
Within one and the same emotion, the attention can shift from one aspect of the situation to another; therefore, the experience itself can fluctuate between different forms of non-self-reflexive and self-reflexive anxiety; and not only that, different forms of non-self-reflexive and self-reflexive anxiety can also co-occur (Kurth 201 8: 69-70; Sartre I943: 66). However, for the purpose of theoretical analysis, they must be disentangled; therefore, in order to facilitate the following discussion, I attribute the three forms of self-reflexive anxiety described in the introductory example to three different persons, Ada, Babak, and Clara.

The introductory example not only illustrates that all cases of self-reflexive anxiety that are bound to specific situations involve two different evaluations; it also illustrates how these evaluations are linked to each other. If the focus of attention is on ourselves, we evaluate ourselves in terms of a possible event whose occurrence we attribute to ourselves; if the focus is on the event, we evaluate the event in terms of what the occurrence of this event might reveal about us as its source. This implies, first, that the question of who or what the possible occurrence of the event is attributed to must be relevant for the evaluation of the event; and second, that its occurrence must at least partly be attributed to oneself (Lewis 2008; Tracy and Robins 2004).

To illustrate this claim, I offer the case of a student who is afraid of failing his final exam in his philosophy course. Since it is his last trial, his failure will be final. As the phenomenon of test anxiety is manifold, he may be afraid of a diverse number of things (Russell and McAuley 1986). First, he may exclusively be afraid of the consequences of his failure, regardless of to whom or what the reasons or causes of his failure (and its consequences) are attributed. Second, the causes and reasons of his possible failure may be relevant for his fear. He may exclusively locate them outside of himself, in the malicious examiner, for example. Or he may at least locate them in part within himself: not having learned enough or not being smart enough for example. It is cases of this last kind that I am interested in; cases in which we fear an event (whose possible occurrence we attribute to ourselves) because of what the occurrence of this event (and its possible consequence) would or might reveal about us. The student, for example, might fear to fail his exam because he values cognitive skills and failing his exam might indicate a lack of them; or he might fear to fail his exam because he takes an aversive stance toward his possible unemployed self and fears that lacking a degree after years of study might result in unemployment. What is characteristic of these cases is that the evaluation of the event in question is based on a concern for what or who we are (Tracy and Robins 2004).

Within the category of self-attributed failure, we can draw further distinctions depending on whether one's failure was caused by something stable or temporary, by something specific or general. These distinctions are commonly used to differentiate different kinds of self-reflexive emotions, such as guilt and shame, hubristic, and achievement-oriented pride (Deonna, Rodogno, and Teroni 20I2: 73-88; Lewis 2008; Tracy and Robins 2004). I hypothesize that similar distinctions can be drawn in the domain of future-directed self-reflexive emotions, although in this case our everyday language does not exhibit the same conceptual 
variety as in the case of past- or present-directed self-reflexive emotions. I leave the proof of this hypothesis for future research.

\section{Varieties of Uncertainty}

According to my introductory definition, the formal object of fear is the property of being an aversive possibility. So, what kind of possibilities are we dealing with in phenomena of self-reflexive anxiety? In the first place, the possibilities in question are epistemic possibilities-that is, possibilities that are dependent on the knowledge of the person who is feeling afraid in a given time at a given place (Gordon I987: 65-85). As pointed out above, all forms of self-reflexive anxiety that I am considering involve two evaluations: a self-evaluation and an evaluation of an event whose occurrence one attributes to oneself. Accordingly, we can distinguish two forms of uncertainty involved in them. The first form of uncertainty concerns the question of whether a given event will take place or has taken place. Usually, this uncertainty comes from the fact that we are dealing with a future event whose occurrence is uncertain, as, for example, in the case of the student who is afraid of failing his final exam. But there are also cases in which the exam and grading have already taken place, but the student still feels afraid because he does not yet know whether he has passed or failed (Roberts 2003: I93).

The second form of uncertainty that is involved in phenomena of self-reflexive anxiety concerns the question of what or who one is, has been, or will become. The uncertainty about the event transfers to one's self-evaluation because it is a self-evaluation in terms of the event whose occurrence is uncertain. The student, for example, is uncertain as to whether he has or lacks some valuable skills because he does not yet know whether he will fail or has failed.

In the case of the student, the possibility of having or lacking the skills in question is merely epistemic - he already has or lacks them but does not yet know whether he does so or not. But we can also think of cases in which we are dealing with a genuine metaphysical possibility. This is the case when the event or action in question is not just (taken to be) expressive of who one is but partly constitutive of it. Take the example of Clara, the hiker who is afraid of jumping down the precipice of her own free will. She is not only uncertain about who she is but also about who she will become. If she decides to jump down the precipice, she will be another person than if she does not decide to do so. Accordingly, we must refine the claim about the relation between the evaluation of the event and the self-evaluation in the previous subsection. In self-reflexive anxiety, we fear an event (whose possible occurrence we attribute to ourselves) because of what the occurrence of this event would or might reveal about us; and/or we fear it because of what the occurrence of the event would or might make us be.

The uncertainty about who one is, has been, or will become may not only result from an uncertainty about the occurrence of a specific event; it can also result from the fact that one is uncertain about whether a specific event indeed would have to be interpreted as expressive and/or constitutive of one's identity. The student may be uncertain about not only whether he will fail his exam and what failing his exam 
would reveal about himself but also whether and to what extent his possible failure would reveal something about himself at all. Similarly, Clara may be uncertain about not only whether she will jump down the precipice and what kind of person jumping down the precipice would make her be but also about whether and to what extent jumping down the precipice would be constitutive of her identity at all.

\section{Practical Identity at Stake}

Up to now, I treated the three cases of self-reflexive anxiety as roughly equivalent. However, the previous subsection indicates that Clara's case is special. She does not (only) see herself confronted with an event whose possible occurrence she takes to be expressive of who she is but (also) with an event whose possible occurrence she takes to be (possibly) constitutive of who she is. Like Ada and Babak, Clara is afraid of an event whose possible occurrence she attributes to herself; and, like them, she evaluates the possible occurrence of this event as an aversive possibility. But her fear is directed at a specific kind of event, namely an action. This makes her case special. Although Ada's and Babak's fear also relate to actions or activities (for example, hiking in the mountains), they are not afraid that they might have the intention to perform a specific action (intentionally jumping down the precipice). Rather, they are afraid of falling down the precipice due to an unintentional mistake or bodily reaction (even if this mistake or reaction occurs while they are performing an intentional action such as climbing a ladder). Actions are specific kinds of events because they are intentional behaviors. As such, they are the epitome of the active dimension of our personhood. This gives rise to the question of how cases like Clara's are possible at all. As Robert Gordon has pointed out, the uncertainty regarding the possible occurrence of an event that is constitutive of the emotion of fear may not solely consist in a deliberative uncertainty'-that is, in the fact that the subject has not yet decided what he or she will do (Gordon I987: 79-84). But is not exactly this the case with Clara? Moreover, the phenomenality of emotions seems to be characterized by a felt passivity of the subject: they are 'passions or ways of being acted on' (Gordon I987: I I8). This might be explained in part by the fact that emotions are directed toward objects that are not completely under our control (Nussbaum 200I: 78). How is it thus possible to be afraid of one's own actions, that is, of the fact that one might perform a specific action?

For cases like Clara's to be possible, three conditions must be met. First, there must be a synchronic or diachronic conflict between our mental attitudes. Clara, for example, may on the one hand desire to jump down the precipice and on the other hand desire not to do so; or she may attribute the desire to jump down the precipice to her future self and see this desire in conflict with her present desires and evaluative beliefs. Analogously, a conflict between the mental attitudes of our past and present self may give rise to self-reflexive anxiety, for example when a person suffering from amnesia sees him- or herself confronted with the possibility of having committed a horrible crime. In this regard, self-reflexive anxiety is a meta-cognition: a mental attitude that is responsive to conflicts between our mental attitudes (Kurth 2018: II4-I 5). 
Second, the person cannot only conceive of the possibility of performing the action in question as a hypothetical possibility; she must conceive of it as a 'real' or 'living option'. When performing actions, we always have alternative possibilities, among them such that would be disastrous. But even if we are aware of having them, we usually do not fear them. We feel certain about what we want to do and what we will do. For example, we are sure that we will bring our philosophical talk to an end, although, hypothetically, we could also, all of a sudden, leave the room in order to enjoy a day at the beach or run amok.

Third and finally, for internal conflicts to evoke self-reflexive anxiety, they may not consist of a mere ambivalence; the person must identify herself with one of the two sides. If Clara was confronted with a mere ambivalence of either jumping down or not jumping down the precipice, she might feel torn between the two conflicting desires, and yet, she would not feel self-reflexively afraid (although she might feel other forms of anxiety such as 'practical anxiety' [Kurth 20I 8: 68-72]). However, at the same time, the person must feel uncertain about who she really is. The action in question poses a threat to her self-conception. What does that mean? According to prominent accounts of practical identity, our practical identity is partly constituted by what we care about (Korsgaard I996: IOI; Frankfurt I988; Velleman 2002). Caring about an object thereby means being affectively attached to the object in question, attributing worth and import to it, and being concerned with its well-being. We can care about a diverse number of things belonging to different metaphysical categories: norms and values, for example, such as the categorical imperative or the value of emancipation, but also particular objects, such as one's nation, child, spouse, friend, or God. Some of the concerns we have are part of our descriptive self-conception: we take them to be constitutive of who we are; others additionally are part of our evaluative self-conception: they are descriptions under which we value ourselves.

From the backdrop of this distinction, we can distinguish two different ways in which actions can challenge our self-conception. First, they may conflict with our descriptive self-conception. Acting contrary to our descriptive self-conception might be experienced as problematic and potentially threatening because it challenges the valuable and/or valued capacity to understand ourselves. Narrative theories of identity, for example, defend the claim that the capacity to understand ourselves is indeed valuable because it is constitutive of being an agent or person (Schechtman 1996; Schechtman 20I4). Self-verification theories suggest that we $d o$ in fact strive for self-understanding (Swann and Read I98I). Finally, theories of moral identity suggest that a discrepancy between our identity and our behavior indeed may express itself in feelings of distress and discomfort (even if the characteristics in question are morally neutral) because personal consistency is an ideal that is constitutive of being a person (Aquino et al. 2009; Blasi I980). For example, a person for whom being a philosopher is part of her descriptive self-conception may be threatened by the fact that she constantly finds herself acting in a manner completely ignorant of the big questions of life, since doing so challenges her identity as a philosopher and, therefore, her (valuable or valued) capacity to understand herself. 
Second, the action may conflict with our evaluative self-conception. Given that our self-esteem is a measure of the degree to which we instantiate the values we care to exemplify, the possibility of acting contrary to our evaluative self-conception is threatening because doing so would reduce our self-esteem. For example, a person for whom being emancipated is part of her evaluative self-description may be threatened by the fact that she finds herself acting completely unemancipated, since doing so challenges her evaluative self-conception and, therefore, lowers her self-esteem. However, in acting in an unemancipated manner, not only may the person's instantiation of the value of emancipation be questioned but so too may her attachment to the value of emancipation itself (Deonna and Teroni 2009; Deonna, Rodogno, and Teroni 20I 2: 99-IO4). As claimed above, our identity is partly constituted by the values we hold. To hold a value 'is to conceive oneself as having a commitment towards that value' (Deonna and Teroni 2009: 46). Some of our values are 'self-relevant values'-that is, values we care to exemplify. Being committed to a self-relevant value means that 'one should try when and if possible to exemplify it and, if one does not, an explanation must be given of why one does not' (Deonna and Teroni 2009: 46). Therefore, the possibility of acting in a manner incompatible with being emancipated does not just threaten the person's self-esteem; it also challenges her evaluative self-conception. Alongside one's exemplification of the value, one's commitment to the value itself is questioned.

To return to the case of Clara, she sees herself confronted with the possibility of willingly jumping down the precipice and thus of entirely and finally negating the value of (her) life and, therefore, all other (self-relevant) values to which she feels committed. This is why her case is so radical. (To be sure, this is not true of all cases of suicide, as a person may also commit suicide in order to uphold a value to which she feels attached.) At the same time, this is why her case (and, more generally, the example of hiking at the abyss) might be misleading: because the fact that one's self-conception is at stake may seem completely irrelevant in the face of the fact that one's life is at stake.

It is thus characteristic of cases like Clara's that they involve a reaction to what we can call an 'existential uncertainty': an uncertainty regarding the question of who we are, want to be, and should become. It is an uncertainty that never can be fully resolved by any epistemic endeavors (Paul 2016: 52-I04). Doing so would presuppose a neutral perspective from which we can evaluate different alternatives of ourselves (Bransen 2000); however, such a neutral perspective does not exist. This suggests that we might be dealing with a form of anxiety that is distinct from what Charlie Kurth (20I8: 67-84) calls environmental, punishment, and practical anxiety. Environmental, punishment, and practical anxiety differ in the kinds of uncertainty to which they are reactions: uncertain physical dangers; uncertain social dangers; or an uncertainty about what 'the correct or appropriate thing to do is' (Kurth 2018: 69). On the contrary, cases like Clara's are characterized by the fact that they involve an existential uncertainty about who we are, want to be, and should become.

However, self-reflexive anxiety may be infused with environmental, punishment, and practical anxiety. Take the example of the student who is afraid of failing his 
exam. He may be so partly because he fears the possible social consequences of his failure such as being mocked by his fellow students. Presuming that our access to our identity is not exclusive-others can question or correct our self-conception-or taking for granted that our identity partly is socially constituted-who we are is partly dependent on who others take us to be-his social uncertainty may not solely be an uncertainty about who he appears to be but a genuine uncertainty about who he is (Sartre I943: 3 I9). Accordingly, social anxiety may involve self-reflexive dimensions, and self-reflexive anxiety may involve social dimensions.

Or take Kurth's (2OI 5 ) example of considering putting one's mother in a nursing home because she is suffering from Alzheimer's and one sees oneself no longer capable of providing her with the care she needs. Kurth presents this case as a case of moral anxiety. As a reaction to an uncertainty about what is the correct or appropriate thing to do, moral anxiety 'prompts epistemic behaviors (e.g., deliberation, information gathering) aimed at resolving the uncertainty at hand' (Kurth 2015: I83) and behaviors aiming at 'minimizing the risks that come along with having to act in the face of such uncertainty (e.g. deferring to 'moral authorities')' (Kurth 20I 5: I79). Self-reflexive anxiety, too, may be a reaction to moral dilemmas and conflicts. As moral anxiety, it is disruptive, may prompt a reassessment of our way of life, and may initiate processes of self-transformation. Therefore, it is potentially valuable. However, moral anxiety as it is conceptualized by Kurth is concerned with the accuracy of one's moral decisions and operates against the backdrop of the belief that there is a correct decision to be drawn (such as not putting one's mother in a nursing home because she is terrified of such places). Self-reflexive anxiety as conceptualized in this subsection is concerned with our identity as persons and operates against the backdrop of the belief that conflicts between different versions of ourselves can never be fully resolved by epistemic means. In the Alzheimer's case, for example, one might be worried that putting one's mother in a nursing home knowing she is terrified of such places would be an expression of egoism and lack of care and finally lead to one's own affective blunting. At the same time, one might be worried that not doing so would overburden oneself with responsibilities that would finally lead to one's own desperation. No matter how one decides, there remains a dilemma between conflicting desires and values. Accordingly, one and the same situation can elicit both forms of anxiety. Depending on whether one's anxiety is focused on the epistemic dimension of moral uncertainty (moral uncertainty as something that, in principle, can be resolved) or on its existential dimension (moral uncertainty as something that, in principle, is unresolvable), it will either take the form of practical anxiety or of existential anxiety.

\section{The Dialectic of Human Existence}

What does the phenomenon of self-reflexive anxiety tell us about human existence? First, cases of self-reflexive anxiety that are bound to a specific situation are characterized by the fact that the anxious person attributes the possible occurrence of an event to herself and yet takes an aversive stance toward its possible occurrence. Therefore, they confront us with a dialectic between self and other, 
activity and passivity inherent to our personhood or even to our agency (Ricœur I992; Stanghellini and Rosfort 20I3). In fearing to become dizzy, Ada sees herself confronted with the dialectic of the agential and non-agential dimensions of personhood. She experiences her bodily reactions as something beyond her control as an agent. However, she still attributes her possible dizziness to herself. Babak, too, sees himself confronted with the fact that not only our agency itself but also the limits and preconditions of our agency are partly constitutive of who we are. He sees himself confronted with limits of his agential powers that are constituted by the capabilities we have at a given moment of time. These capabilities may be partly shaped by our past and our environment and be preconditioned by our biology. Although he attributes the possibility of making a fatal mistake to himself, he regards his possible misstep as something beyond his control. In phenomena of self-reflexive anxiety like Ada's and Babak's we see ourselves confronted with the fact that the non-agential dimensions of our personhood-the fact that 'we are shaped by our physiological nature, by our environment, and by our past history' (Rosfort and Stanghellini 2009: 254)-do not only constitute conditions of our agency but also may have the potential to destroy our personhood as such. This makes their situation particularly threatening. Clara, finally, as outlined above, sees herself confronted with a dialectic inherent in our agency itself.

Second, in phenomena of self-reflexive anxiety, the boundaries between the passive and active dimensions of our personhood are experienced as blurry. If there were no passivity involved, we would not be anxious. If there were no activity involved, we would not be self-reflexively anxious. While we may be incapable of directly influencing our bodily reactions, we may try to influence them indirectly. Ada may, for example, sit down in order to avoid severe consequences of feeling dizzy. While at a given moment of time, we may feel and indeed be completely at the mercy of our bodily reactions and capabilities, things look different if we take into account the diachronic nature of personhood. Babak may at least partly feel responsible for having or lacking the skills to reach the summit because of (not) having invested the necessary effort in acquiring and sustaining them. The student who is afraid of failing his exam may not only question his intellectual abilities and knowledge but also his desires and value commitments, since, if he really wanted and wants to achieve a degree in philosophy, why did he not work harder toward this end? Accordingly, the possibility of failing his exam may not only threaten his self-esteem but also his evaluative self-conception, as it is the case with Clara.

At the same time, in my analysis of the case of Clara, I emphasized that rather than seeing ourselves confronted with a radical kind of freedom, we feel somewhat passive and powerless with regard to our own actions and our identity expressed in our actions. Indeed, without feeling so, we would not fear the action in question. Just as in forms of self-reflexive anxiety directed at our own bodily reactions or in the fear of our own failure we usually do not experience ourselves as mere bystanders of our reactions and our identity expressed in our reactions, so too in forms of self-reflexive anxiety directed at our own actions we do not experience ourselves as mere authors of our actions and our identity expressed in our actions. 
To summarize, in the phenomenon of self-reflexive anxiety, rather than just seeing ourselves confronted with the fact that our personhood is not restricted to our agency, we see ourselves confronted with the unclear boundaries of our agential powers and, therefore, of our responsibility. Together with the boundaries between the active and passive dimension of our personhood and agency, the boundaries between the three forms of anxiety that I distinguished are blurry. We see ourselves confronted with our (all too) limited freedom.

Third and finally, although the boundaries between the three cases of self-reflexive anxiety are blurry, they still differ in the degree to which we feel responsible for the possible occurrence of the event in question. On one end of the scale are cases in which we are afraid of an event that we attribute to ourselves but for whose possible occurrence we do not feel responsible at all. At the other end of the scale are cases in which we are afraid of an event that we attribute to ourselves and that we feel fully responsible for. Since self-reflexive anxiety always involves some level of felt passivity and some level of felt activity, all phenomena of self-reflexive anxiety are situated in between these two poles. Even the most extreme cases contain a moment of ambiguity. Still, it is of great significance whether we are dealing with one or the other extreme or with cases that fall in between. Although in all cases we are confronted with our all too limited freedom, our degree of freedom and the strength of our chains vary significantly.

\section{Self-Reflexive Emotions Reconsidered}

As I argued, the debate on self-reflexive emotions is focused on emotions such as shame, guilt, or pride that are necessarily self-reflexive (or at least self-reflexive in their paradigmatic cases) and (at least in their paradigmatic cases) directed at our past or present self. Therefore, an analysis of self-reflexive anxiety is not only of intrinsic value but also promises to shed light on our understanding of self-reflexive emotions in general. Let me give three examples of how it does so.

First, my discussion of the phenomenon of self-reflexive anxiety has implications for our understanding of the concept of self-reflexive emotions as such. My initial definition of self-reflexive emotions was based on the claim that emotions are evaluative representational states of mind. As I argued, this definition suggests defining self-reflexive emotions as affective states in which we evaluate ourselves. Thus, the self-reflexivity was located at the level of the material object of the emotion. But my discussion suggests that self-reflexive anxiety is also based on a concern for ourselves, for what or who we are. Interestingly, there are psychological theories of self-reflexive emotions that place this kind of self-centeredness at the heart of their definition of self-reflexive emotions: 'In the literature, emotions have been distinguished on a continuum ranging from basic to self-reflexive or self-conscious emotions. . . . All emotions are triggered by a match or, more frequently, a mismatch between the concerns of the organism and the event the organism is confronted with. The two poles of the continuum are differentiated by the type of concerns that are involved. At the basic pole emotions are characterized by a (mis)match in survival concerns. . . . At the self-conscious pole the person's self is at stake' (Fontaine 2009: 357). 
This passage alerts us to the fact that we may define self-reflexive emotions not just with reference to their material object but also with regard to the concerns involved in them. As an illustration, I offer an example described by Jessica Tracy and Richard Robins. A man camping in the woods with his girlfriend is confronted with an approaching bear. As the authors note, 'he is likely to appraise this event as relevant to his survival goals and feel fear-a basic emotion. Yet, he may also appraise the event as relevant to his identity goals: 'he may run and scream in terror, which could generate shame or guilt because he has failed to live up to his "boyfriend as protector" identity, particularly if he leaves his girlfriend behind to become bear food' (Tracy and Robins 2004: III). The emotions are thus classified according to what one takes to be at stake: one's survival or one's identity. Whereas, at first sight, defining self-reflexive emotions as emotions in which we evaluate ourselves and defining them as emotions in which one's self is at stake may seem to constitute two independent kinds of classification, my discussion of the phenomenon of self-reflexive anxiety shows that in being afraid of ourselves, we are, at the same time, afraid for ourselves (Heidegger 2006: I 849I). The man in the example above is self-reflexively afraid of running away because it threatens his 'boyfriend as protector' identity. This invites us to reconsider the initial intuition that both kinds of definitions are independent of each other and indicates that theories that one-sidedly focus on the material object of self-reflexive emotions without reflecting on the concerns involved in them might be badly incomplete. Moreover, my analysis of the different forms of self-evaluations that may be involved in feelings of self-reflexive anxiety helps to obtain a more accurate understanding of what 'the person's self is at stake' means (Fontaine 2009: 357).

Second, my differentiation of three forms of self-reflexive anxiety and my discussion of their similarities and differences shed light on the question of whether self-attribution or felt responsibility are crucial for an emotion to be classified as self-reflexive. As I argued, there is an ambiguity in our conception of self-reflexive emotions with regard to the question of whether it is sufficient for an emotion to be classified as self-reflexive to attribute the feature or event that is evaluated to oneself or whether, in addition, we have to feel responsible for having the feature or having brought about the event in question. At first sight, this ambiguity seemed to be a problem for our conception of self-reflexive emotions or maybe even for the specific conception of self-reflexive emotions to which I referred. If this were the case, a development of our understanding would consist in resolving the ambiguity in favor of one or the other defining feature. Contrarily, my analysis suggests that the ambiguity derives not from our thinking but from the subject matter itself. We can evaluate ourselves in terms of features (such as our skin color) for which we do not feel at all responsible. Therefore, self-attribution is sufficient for self-reflexive emotions. But we can also evaluate ourselves in terms of events for whose occurrence we, as agents, feel fully responsible, as in the case of feeling guilty for having intentionally hurt someone. The fact that both kinds of evaluations are self-evaluations reflects an ambiguity within our selfhood as such: an ambiguity between passivity and activity, powerlessness and power, being a social, historical, and biological being and 
being an agent. Different types of self-reflexive emotions, such as guilt and shame, thereby may emphasize different dimensions of our selfhood.

Yet, my analysis suggests that this is not the whole picture: not only are we made up of these two distinct parts, but we can also reflexively relate to them. We are not mere bystanders with regard to our nature, nor are we mere authors with regard to our practical identity. In this regard, the scale between cases of self-attribution without any kind of felt responsibility and cases of self-attribution with a fully fledged sense of responsibility is a gradual one.

At the same time, my analysis does justice to our intuition that there is a significant difference between cases of self-reflexive emotions in which our agency is touched and cases in which this is not so. Cases of self-reflexive emotions that are directed at our own actions (or features and events that relate to our actions) are special because as we feel responsible for our actions, we first and foremost see ourselves confronted with our identity as something brought about by ourselves. By contrast, cases of self-reflexive emotions that are directed at events or features for which we do not feel responsible are special because they confront us with parts of ourselves that are completely beyond our control and yet may be part of who or what we are.

Third and finally, my disambiguation of different forms of uncertainty that may be involved in phenomena of self-reflexive anxiety shows in what sense and to what extent phenomena of shame may contain or even be constituted by phenomena of self-reflexive anxiety. As I argued, the uncertainty about who we are, have been or will become may not only result from an uncertainty about whether a given event has taken place or will take place; it may also result from the fact that one is uncertain about whether a given event indeed would have to be interpreted as expressive and/or constitutive of one's identity. Importantly, this form of uncertainty can also occur when one is certain about the occurrence of the event in question, as it is the case in past- or present-directed self-reflexive emotions. For example, in non-prospective shame, we are certain about having a certain feature or having behaved or acted in a specific way. In this regard, it is a 'factive emotion' (Gordon I987: 45-64). However, we still may be uncertain about whether and to what extent having the feature in question or having behaved or acted in a specific way indeed has to be interpreted as an expression of what or who we are.

This seems to be the kind of uncertainty to which Deonna and Teroni refer when they claim that in the feeling of shame, we experience our identity as threatened:

In shame, one realizes that a value about the exemplification of which one cares is not even minimally exemplified. One apprehends the non-exemplification of this value as due to one's exemplifying a (dis) value that threatens one's commitment to try to exemplify this value... . And because these commitments are part and parcel of his identity, feeling shame threatens his identity in the following way. The evaluation, in shame, is not the punctual realization that one has failed to exemplify a self-relevant value, but rather puts into question one's very ability to discharge the commitments that go with it: even a 
minimal exemplification of the value is perceived by the subject as beyond reach. (Deonna and Teroni 2009: 46-47, my emphasis)

Similarly, David Velleman takes shame to be constituted by the perception of a threat. However, for him, it is not a threat to our self-conception but to our being recognized as a self-presenting creature (Velleman 200I). Self-presenting creatures are creatures that have the capacity to resist their inclinations and to control which desires their behavior expresses. By making these choices consistently over time, they create a coherent public image. This in turn, according to Velleman, is not only a precondition for making sense of one's own life but also for being eligible for social interaction. We experience shame if our being recognized as a self-presenting creature is threatened. Shame thus involves an uncertainty about whether our behavior is to be interpreted as disqualifying us as self-presenting creatures. According to Velleman (2003), guilt essentially involves a form of anxiety, too, along with a sense of diminished self-worth. It is an anxiety about having forfeited practical trust. However, the person who is feeling guilty is certain that the withdrawal of trust is warranted. Her uncertainty only pertains to the question of whether the feared punishment will take place. Therefore, the anxiety in question is a world- rather than a self-directed form of anxiety.

No matter whether we follow Deonna and Teroni's or Velleman's analysis of shame, this implies that the traditional classification of shame as a plain factive emotion is at least incomplete. One might even classify it as a form of (self-reflexive) anxiety-as Velleman (200I: 50) does-although the cases of self-reflexive anxiety discussed in this paper involve yet another dimension of uncertainty—namely an uncertainty about whether a specific event will take place or has taken place.

RUTH REBECCA TIETJEN (C) HEINRICH HEINE UNIVERSITY DÜSSELDORF Ruth.Tietjen@hhu.de

\section{References}

Aquino, Karl, Dan Freeman, Americus Reed, Will Felps, and Vivien K. G. Lim. (2009) 'Testing a Social-Cognitive Model of Moral Behavior: The Interactive Influence of Situations and Moral Identity Centrality'. Journal of Personality and Social Psychology, 97, I23-4I.

Blasi, Augusto. (I980) 'Bridging Moral Cognition and Moral Action: A Critical Review of the Literature'. Psychological Bulletin, 88, I-45.

Bransen, Jan. (2000) 'Alternatives of Oneself: Recasting Some of Our Practical Problems'. Philosophy and Phenomenological Research, 60, $38 \mathrm{I}-400$.

Clark, David A., and Adam S. Radomsky. (20I4) 'Introduction: A Global Perspective on Unwanted Intrusive Thoughts'. Journal of Obsessive-Compulsive and Related Disorders, 3, 265-68.

Deonna, Julien, Raffaele Rodogno, and Fabrice Teroni. (2012) In Defense of Shame: The Faces of an Emotion. Oxford: Oxford University Press.

Deonna, Julien, and Fabrice Teroni. (2009) 'The Self of Shame'. In Mikko Salmela and Verena E. Mayer (eds.), Emotions, Ethics, and Authenticity (Amsterdam: John Benjamins), 33-50.

Deonna, Julien, and Fabrice Teroni. (2012) The Emotions: A Philosophical Introduction. London: Routledge. 
Fontaine, Johnny. (2009) 'Self-Reflexive Emotions'. In David Sander and Klaus R. Scherer (eds.), The Oxford Companion to Emotion and the Affective Sciences (Oxford: Oxford University Press), $357-59$.

Frankfurt, Harry G. (I988) The Importance of What We Care About: Philosophical Essays. Cambridge: Cambridge University Press.

Goldie, Peter. (2009) The Emotions: A Philosophical Exploration. Oxford: Oxford University Press.

Gordon, Robert M. (I987) The Structure of Emotions: Investigations in Cognitive Philosophy. Cambridge: Cambridge University Press.

Heidegger, Martin. (2006) Sein Und Zeit. Tübingen: Max Niemeyer Verlag.

Helm, Bennett W. (200I) Emotional Reason: Deliberation, Motivation, and the Nature of Value. Cambridge: Cambridge University Press.

James, William. (2002) The Varieties of Religious Experience: A Study in Human Nature. Mineola: Dover Publications.

Kierkegaard, Søren. (1980) The Concept of Anxiety: A Simple Psychologically Orienting Deliberation on the Dogmatic Issue of Hereditary Sin. Princeton, NJ: Princeton University Press.

Konzelmann Ziv, Anita. (20II) 'Self-Evaluation: Philosophical Perspectives'. In Anita Konzelmann Ziv, Keith Lehrer, and Hans B. Schmid (eds.), Self-Evaluation: Affective and Social Grounds of Intentionality (Dordrecht: Springer), I-32.

Konzelmann Ziv, Anita, Keith Lehrer, and Hans Bernhard Schmid, eds. (20II) Self-Evaluation: Affective and Social Grounds of Intentionality. Dordrecht: Springer.

Korsgaard, Christine Marion. (I996) The Sources of Normativity. Cambridge: Cambridge University Press.

Kurth, Charlie. (2015) 'Moral Anxiety and Moral Agency'. In Mark Timmons (ed.), Oxford Studies in Normative Ethics, Volume 5 (Oxford: Oxford University Press), I7 I-95.

Kurth, Charlie. (2018) The Anxious Mind: An Investigation of the Varieties and Virtues of Anxiety. Cambridge, MA: MIT Press.

Lewis, Michael. (2008) 'Self-Conscious Emotions: Embarrassment, Pride, Shame and Guilt'. In Michael Lewis, Jeannette M. Haviland-Jones, and Lisa F. Barrett (eds.), Handbook of Emotions (New York: Guilford Press), 742-56.

Lyons, William. (1980) Emotion. Cambridge: Cambridge University Press.

Markus, Hazel, and Paula Nurius. (I986) 'Possible Selves'. American Psychologist, 4I, 954-69.

Nussbaum, Martha C. (200I) Upheavals of Thought: The Intelligence of Emotions. Cambridge: Cambridge University Press.

Paul, Laurie A. (20I6) Transformative Experience. Oxford: Oxford University Press.

Radomsky, Adam S., Gillian M. Alcolado, Jonathan S. Abramowitz, Pino Alonso, Amparo Belloch, Martine Bouvard, David A. Clark, et al. (20I4) 'Part I. You Can Run but You Can't Hide: Intrusive Thoughts on Six Continents'. Journal of Obsessive-Compulsive and Related Disorders, 3, 269-79.

Reiss, Steven. (I99I) 'Expectancy Model of Fear, Anxiety, and Panic'. Clinical Psychology Review, II, I4 I-53.

Ricœur, Paul. (1992) Oneself as Another. Chicago: University of Chicago Press.

Roberts, Robert C. (2003) Emotions. An Essay in Aid of Moral Psychology. Cambridge: Cambridge University Press.

Rosfort, René, and Giovanni Stanghellini. (2009) 'The Person in between Moods and Affects'. Philosophy, Psychiatry, and Psychology, I6, 25 I-66.

Russell, Dan, and Edward McAuley. (I986) 'Causal Attributions, Causal Dimensions, and Affective Reactions to Success and Failure'. Journal of Personality and Social Psychology, 50, I I 74-85.

Sartre, Jean-Paul. (1943) L’ Être Et Le Néant. Paris: Gallimard.

Schechtman, Marya. (I996) The Constitution of Selves. Ithaca, NY: Cornell University Press.

Schechtman, Marya. (2014) Staying Alive: Personal Identity, Practical Concerns, and the Unity of a Life. Oxford: Oxford University Press.

Schulz, Walter. (1965) 'Das Problem Der Angst in Der Neueren Philosophie'. In Hoimar von Ditfurth (ed.), Aspekte Der Angst. Starnberger Gespräche 1964 (Stuttgart: Thieme), I-23.

Spielberger, Charles D., and Peter R. Vagg, eds. (1995) Test Anxiety: Theory, Assessment and Treatment. Washington, DC: Taylor \& Francis. 
Stanghellini, Giovanni, and René Rosfort. (2013) Emotions and Personhood: Exploring Fragility, Making Sense of Vulnerability. Oxford: Oxford University Press.

Swann, William B., and Stephen J. Read. (198I) 'Self-Verification Processes: How We Sustain Our Self-Conceptions'. Journal of Experimental Social Psychology, I7, 35 I-72.

Tappolet, Christine. (2010) 'Emotion, Motivation, and Action: The Case of Fear'. In Peter Goldie (ed.), The Oxford Handbook of Philosophy of Emotion (Oxford: Oxford University Press), $325-45$.

Taylor, Gabriele. (I985) Pride, Shame, and Guilt. Emotions of Self-Assessment. Oxford: Oxford University Press.

Teroni, Fabrice. (2007) 'Emotions and Formal Objects'. Dialectica, 6I, 395-4I 5.

Tietjen, Ruth Rebecca. (2019) Am Abgrund: Philosophische Theorie der Angst und Übung in philosophischer Freiheit. Paderborn: mentis.

Tillich, Paul. (2000) The Courage to Be. New Haven, CT: Yale University Press.

Tracy, Jessica L., and Richard W. Robins. (2004) 'Putting the Self into Self-Conscious Emotions: A Theoretical Model'. Psychological Inquiry, I 5, I03-25.

Tracy, Jessica L., Richard W. Robins, and June Price Tangney, eds. (2007) The Self-Conscious Emotions: Theory and Research. New York: Guilford Press.

Velleman, J. David. (200I) 'The Genesis of Shame'. Philosophy and Public Affairs, 30, 27-52.

Velleman, J. David. (2002) 'Identification and Identity'. In Sarah Buss and Lee Overton (eds.), Contours of Agency: Essays on Themes from Harry Frankfurt (Cambridge, MA: MIT Press), 9I-I23.

Velleman, J. David. (2003) 'Don't Worry, Feel Guilty'. In Anthony Hatzimoysis (ed.), Philosophy and the Emotions (Cambridge: Cambridge University Press), $235-48$.

Wells, Adrian. (2007) 'Cognition about Cognition: Metacognitive Therapy and Change in Generalized Anxiety Disorder and Social Phobia'. Cognitive and Behavioral Practice, I4, I 8-25.

Zeidner, Moshe, and Garath Matthews. (2005) 'Evaluation Anxiety: Current Theory and Research'. In Andrew J. Elliot and Carol S. Dweck (eds.), Handbook of Competence and Motivation (New York: Guilford Publications), I4 I-63.

Zinck, Alexandra. (2008) 'Self-Referential Emotions'. Consciousness and Cognition, 17, 496-505.

Zinck, Alexandra. (20I I) Emotions Hold the Self Together: Self-Consciousness and the Functional Role of Emotion. Paderborn: mentis. 